\title{
Undak Usuk Bahasa Jepang dan Bahasa Jawa : Sebuah Perbandingan
}

\author{
HARTATI*)
}

\begin{abstract}
ABST RAK
Di antara sekian banyak bahasa-bahasa di dunia, bahasa Jepang memiliki ciri yang identik dengan bahasa Jawa, bahasa Korea, dan Tibet, yang terkenal sekali karena mempunyai sistem undak usuk yang teratur dan rumit. Bahasa Jepang dan bahasa Jawa merupakan dua bahasa yang tidak serumpun, meskipun sama-sama memiliki sistem undak usuk tetapi secara tipologi bahasa berbeda. Penelitian ini berjudul Undak Usuk Bahasa Jepang dan Bahasa Jawa:sebuah perbandingan. Tujuan dari penelitian ini adalah untuk mendeskripsikan persamaan dan perbedaan undak usuk bahasa Jepang dan bahasa Jawa, serta mendeskripsikan faktor-faktor apa saja yang memengaruhi pemilihan varian undak usuk dalam bahasa Jepang dan bahasa Jawa. Metode yang digunakan adalah metode deskriptif kontrastif yang meliputi pengumpulan data, analisis data, dan perbandingan hasil analisis data, atau juga dikenal dengan sebutan analisis kontrastif, yaitu metode sinkronis dalam analisis bahasa untuk menunjukkan persamaan dan perbedaan antara bahasa-bahasa atau dialek-dialek untuk mencari prinsip yang dapat dijabarkan dalam masalah praktis. Hasil penelitian ini berupa deskripsi tentang persamaan dan perbedaan undak usuk bahasa Jepang dan bahasa Jawa serta aplikasinya. Meskipun sama-sama memiliki undak usuk antara kedua bahasa tersebut tetapi hal itu tidak selalu menguntungkan bagi para siswa. Sehingga yang terjadi adalah kesulitan-kesulitan yang selama ini mungkin dialami oleh para pembelajar bahasa Jepang khususnya karena sebagian besar adalah penutur bahasa Jawa. Penelitian kontrastif ini tentu saja sedikit banyak akan membantu para pengajar bahasa Jepang untuk siswa penutur bahasa Jawa atau sebaliknya dalam penyusunan silabus pengajaran.

Kata kunci: undak usuk, bahasa Jepang, bahasa Jawa, kontrastif
\end{abstract}

\section{ABSTRACT}

Among so and so much languages in this world, Japanese has an identical characteristic with Javanese, Korean, and Tibetan, which is well known for the similarity in having regular and complicated speech level system. Japanese and Javanese constitute belong to different family of languages, even both of them having an speech level system, but belong to different languange in topology manner. This research has purpose to describe the similarity between Japanese's and Javanese's speech level and to describe factors that influens the choice of language variation conserning with speech level of Japanese as well as Javanese. This research used contrastive descriptive method, which comprise of data gathering, data analysis, and result of comparison, such data analysis for pointing their similarities and disparaties among languages or dialects, to find out its principal, which is possibly to be explained on the practical complicatio. Through methods mentioned above, results had attained in form of description about similarities and disparities between Japanese's and Javanese's speech level, with their applications. Indeed 


\section{JOURNAL OF
JAPANESE LANGUAGE
EDUCATION \& \\ LINGUISTICS}

both of them have speech level but it were not always giving benefit for students, because there much certain prominent points that able to differentiate speech level between both languages. Thus, as last result attained from this research made author may predict any difficulties, which possibly experienced by student, especially whom study Japanese, because most of them weer Javanese narrator. Beside that, surely this contrastive research will assist Japanese instructors for Javanese students or otherwise during teaching syllabus arranging.

Keyword : speech level,Japanese, Javanese,contrastive

\section{A. PENDAHULUAN}

Bahasa tidak pernah lepas dari masyarakatnya. Masyarakat bahasa adalah suatu masyarakat yang semua anggotanya memiliki bahasa bersama paling tidak satu ragam ujaran dan norma-norma pemakaiannya yang cocok.

M enurut konsep sosiolinguistik, struktur masyarakat yang selalu bersifat heterogen (tidak pernah homogen) memen garuhi wujud bahasa dal am pemakaiannya. Struktur masyarakat tersebut di pengaruhi oleh berbagai faktor, yaitu berupa aspek situasi seperti siapa yang berbicara (who speaks), dengan siapa (wih whom), diamana (where), kapan (when), dan untuk apa (to what end) (Fishman, 1975:15). Selain aspek situasi, latar belakang penutur seperti usia, jenis kelamin, pendidikan dan tingkat sosial juga sangat memengaruhi terbentuknya struktur masyarakat.

Sosiolinguistik memandang wujud bahasa dalam hubungannya dengan pemakai bahasa di dalam masyarakat karena di dalam kehidupan bermasyarakat manusia tidak lagi sebagai individu saja, akan tetapi sebagai bagian masyarakat sosial. O leh karena iu, segala sasuatu yang dilakukan oleh manusia dalam bertutur akan selalu dipengaruhi situasi atau kondisi di sekitarnya. Pemakaian bahasa dikontrol oleh faktor-faktor yang bersifat sosial dan situasional, berbagai jenis variasi bahasa seperti ragam bahasa (formal atau nonformal), laras tutur (speech level), register, dialek, sosiolek, kronolek, dan sebagainya yang berlatar belakang konteks sosial dan hubungan struktur kemasyarakatan dengan wujud bahasa menjadi objek kajian sosiolinguistik. $M$ isalnya dalam sosiolinguistik bahasa Jawa, seseorang yang memiliki status sosial lebih rendah akan memberikan laras tutur 
yang tinggi (krama) kepada mitra wicaranya yang memiliki status sosial yangtinggi. Sebaliknya, sang mitra wicara akan memberikan laras tutur yang lebih rendah (ngoko).

Tingkat tutur (undak usuk) merupakan variasi bahasa pemakaiannya didasarkan pada tingkat-tingkat kelas atau status sosial interlokutornya (Suwito, 1983). K eigo atau kaidah bentuk hormat dalam bahasa Jepang adalah istilah yang sepadan dengan U ndak U suk Basa dalam bahasa Jawa. Kaidah bentuk hormat merupakan aturan pemakaian kata-kata sonkeigo (kata hormat), teineigo (kata sopan), dan kenjougo (kata merendahkan diri).

$M$ isalnya pada contoh dibawah ini:

a. Tomodachi kara hon o karimasu

Teman dari buku partikel meminjam

'kula nyambut buku saking kanca/ rencang kula'

b. Nani o karireru?

Apa partikel meminjam?

'arep nyilih apa?'

c. Gohon o haishaku dekimasu ka?

Buku(sopan) partikel meminjam (sopan) bisa penanda kt tanya(apakah)

'Punapa kula kepareng nyuwun ngampil buku?'

Kalimat pertama di atas merupakan kalimat ragam sopan, baik dalam bahasa Jepang maupun padanannya dalam bahasa Jawa. Verba karimasu [nyambut] sebagai penentu dalam kalimat (a) termasuk ke dalam jenis sonkeigo [krama]. Tetapi kadar hormatnya dibawah kalimat ketiga. Pada kalimat kedua, tingkat kesopanannya lebih ren dah daripada kalimat pertama dan ketiga. Dalam bahasa Jepang, bentuk verba bantu reru/ rareru masih termasuk jenis sonkeigo [krama], meskipun kadar hormatnya sedikit lebih rendah. Tetapi, ternyata padanan kata karireru yang dipadankan dengan kata nyilih dalam bahasa Jawa termasuk 


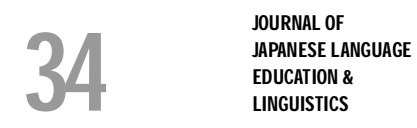

dalam ngoko. Berarti ini tidak sesuai dengan definisi sonkeigo yang selalu dipadankan dengan krama dalam bahasa Jawa. Go pada kalimat tiga (c) menunjukkan rasa hormat, merupakan jenis turunan dari kata dasar hon. Biasanya kata tersebut di letakkan di depan/ awal kata yang akan dibuat sopan. Padanan kata hon dalam bahasa Jawa adalah 'kagunganel ipun' atau 'kang/ ingkang'. Selain itu, pada kalimat tiga juga terdapat verba haishaku dekimasu [nyuwun ngampil] yang sepadan dengan krama inggil dalam bahasa Jawa dan merupakan bentuk sopan dari kata kariru/karimasu [nyilih/ nyambut]. Dalam hal ini pembicara meninggikan orang yang dipinjami buku olehnya dan karena mungkin saja statusnya lebih tinggi atau orang yang disegani. $\mathrm{H}$ al ini merupakan kategori sonkeigo dalam bahasa Jepang.

Ditinjau dari segi sosiolinguistik, bahasa Jawa memilki stratifikasi. Penggunaan ragam basa dengan sintaksis, dan leksikon krama, intonasi, penggunaan kata sapaan yang tepat disertai dengan ciri-ciri linguistis seperti suara yang lembut, senyuman atau gerak tubuh yang sesuai dengan adat istiadat dalam kebudayaan yang bersangkutan merupakan bagian yang sangat vital dalam bertutur kata. Begitu pula dalam bahasa Jepang, ciri-ciri linguistis tersebut selalu memengaruhi dalam setiap penggunaan tingkat tutur. Adanya bahasa laki-laki dan bahasa perempuan juga turut berpengaruh terhadap pemilihan kata yang tepat dalam setiap penggunaannya.

Alasan mengapa penelitian ini harus dilakukan saat mempelajari bahasa Jepang dan bahasa Jawa, ternyata penulis melihat fenomena yang unik dari kedua bahasa tersebut karena sama-sama mempunyai sistem undak usuk meskipun secara tipe bahasa atau susunan pola kalimat kedua bahasa tersebut berbeda. Kemiripan tersebut tidak selalu menguntungkan siswa pembelajar bahasa Jepangataupun sebaliknya. Hal ini disebabkan oleh faktorfaktor yang memengaruhi sistem undak usuk dal am bahasa Jepang dan bahasa Jawa berbeda. M isalnya, bentuk teineigo atau ragam sopan dalam bahasa Jepang digunakan untuk menyatakan rasa hormat dan memperindah suatu pokok pembicaraan agar 
terdengar lebih enak dan bagus, dengan tanpa memperhatikan derajat sosial, umur, ataupun tingkat kekerabatan pembicara terhadap mitra wicara. Ragam ini banyak digunakan oleh kaum perempuan. Padan an teineigo ini dalam bahasa Jawa adal ah ragam krama, tetapi krama dalam bahasa Jawa sangat dipengaruhi oleh derajat sosial, ataupun tingkat kekerabatan. $\mathrm{H}$ al inilah yang terkadang membuat bingung para pembelajar, bahkan sering terjadi kesalahan pemilihan padanan dalam bahasa sasaran. Selain itu, dalam bahasa Jawa tidak ada perbedaan bahasa lakilaki dan bahasa perempuan.

O leh karena bahasa Jepang dan bahasa Jawa bukan bahasa yang serumpun, maka salah satu upaya untuk meneliti adalah dengan mengontraskan dalam suatu analisis kontrastif antara bahasa Jepang dan bahasa Jawa ditinjau dari segi linguistiknya. Studi kontrastif mempunyai peranan penting terutama dalam proses pengajaran bahasa asing. Dengan menggunakan analisis kontrastif, dapat ditemukan perbedaan atau persamaan yang mendasar dari kedua bahasa yan g diteliti, dalam hal ini mengenai undak usuk bahasa Jepang dan bahasa Jawa, sehingga memungkinkan untuk membantu mempermudah penyusunan silabus pengajaran, terutama untuk pengajaran bahasa Jepang di Indonesiayang mayoritas siswanya berlatar belakang suku Jawa.

\section{B. METODE PENELITIAN}

M enurut Jack Richards (1985), linguistik kontrastif adalah perban dingan sistem linguistik dari dua bahasa. Sistem linguistik itu bisa berupa suatu sistem bunyi atau sistem gramatikal. Analisis kontrastif mulai berkembang dan digunakan pada tahun 1950 dan tahun 1960-an sebagai aplikasi atau penerapan linguistik struktural ke dalam pen gajaran suatu bahasa, yang berdasar pada an ggapan-anggapan sebagai berikut.

1. Kesulitan-kesulitan dasar dalam mempelajari sebuah bahasa baru disebabkan oleh pengaruh bahasa pertama.

2. Kesulitan-kesulitan ini dapat diprediksi oleh an alisiskontrastif. $M$ ateri-materi pen gajaran dapat dibuat den gan mengacu pada 
hasil-hasil penelitian tentang analisis kontrastif dengan mengurangi dampak dari pengaruh bahasa pertama.

Joos Martin (dalam Soetomo, 1994) mengasumsikan bahwa sesungguhnya tidak ada bahasa bahasa yang bersifat monolitik, maka suatu isolasi gaya-gaya bahasa yang menunjukkan undak usuk penggunaannya (level of usage) perlu dilakukan. Seperti halnya dalam bahasa Jepang dan bahasa Jawa undak usuk dan aplikasinya ada dalam setiap masyarakat pengguna bahasa tersebut, untuk kemudian akan menjadi topik dalam penelitian ini.

M etode yang digunakan dalam penelitian ini adalah metode deskriptif kontrastif yang meliputi pengumpulan data, analisis data, dan perbandingan hasil analisis data, atau juuga dikenal dengan sebutan analisis kontrastif, yaitu metode diakronis dalam analisis bahasa untuk menunjukkan persamaan dan perbedaan antara bahasa-bahasa atau dialek-dialek untuk mencari prinsipprinsip yang dapat dijabarkan dalam masalah praktis (K ridalaksana, 1982).

Studi kontrastif adalah suatu studi yang mempunyai peranan penting dalam proses pengajaran bahasa asing. Dalam proses pengajaran sebuah bahasa, yang paling penting adalah menentukan aspek-aspek kesamaan serta perbedaan dua bahasa yang diperbandingkan. Analisis kontrastif adalah suatu metode analisis pen gkajian kontrastif, ini menunjukkan kesamaan dan perbedaan antara dua bahasa den gan tujuan untuk menemukan prinsip yang dapat diterapkan pada masalah praktis dalam pengajaran bahasa atau terjemahannya.

Dalam analisis kontrastif dikenal adanya pola prosedur analisis. Pola itu dimaksudkan agar sistem kebahasaankebahasaan yang dibandingkan dapat diamati dengan lebih baik, Nickel (dalam et al., 1991:4). Lazimnya prosedur itu dibedakan menurut model yang dikemukakan kerangka teori struktural atau taksonomi dan tran sformasi (James, 1980:36). Analisis dilakukan secara terpisah, yaitu bahasa Jepang dan bahasa Jawa diamati dari sudut pandang pendekatan masing-masing bahasa lalu diperbandingkan untuk menemukan perbedaan bentuk bahasa 
dan makna bahasa yang menjadi ciri khas bahasa yang bersangkutan. Selanjutnya, dengan metode analisis kontrastif secara khusus dilakukan perbandingan untuk menghasilkan sejumlah fakta berupa persamaan dan perbedaan antara undak ususk bahasa Jepang dan bahasa Jawa.

\section{HASIL DAN PEMBAHASAN}

Pada zaman purba dan pertengahan di Jepang, sistem undak usuk ditititkberatkan pada hierarki dalam masyarakat. Sikap pembicara terhadap mitra wicara dengan memperhatikan status sosial, pangkat, asal usul seseorang yang diacu, apakah dari kalangan bawah, menengah, atau dari kalangan atas seperti bangsawan atau kalangan istana, menentukan memakai atau tidaknya bentuk hormat dan kadar hormat yang hendak dipakai dalam tuturannya. Kelompok kata yang dipakai untuk menunjukkan sikap hormat ialah sonkeigo (krama inggil) dan kenjougo (krama adhap) (Supardjo, 1999).

Berikut ini skema garis besar undak usuk modern bahasa Jepang dan perbandingannya dalam bahasa Jawa.

\begin{tabular}{|c|c|}
\hline BAHASA JEPANG & BAHASA JAWA \\
\hline Keigo (Ragam Hormat) & Unggah-Ungguh \\
\hline 1.Ragam Futsuu & 1.Basa Ngoko \\
\hline $\begin{array}{l}\text { a. Ragam futsuu tanpa sonkeigo atau } \\
\text { kenjougou }\end{array}$ & a. Ngoko-lugu (ngoko) \\
\hline $\begin{array}{l}\text { b. Ragam futsuu dengan sonkeigo atau } \\
\text { kenjougo }\end{array}$ & b. Ngoko-alus \\
\hline 2.Ragam Teinei & 2.Basa Krama \\
\hline $\begin{array}{l}\text { a. Ragam teinei tanpa sonkeigo atau } \\
\text { kenjougo }\end{array}$ & a. Krama limrah \\
\hline $\begin{array}{l}\text { b. Ragam teinei dengan sonkeigo atau } \\
\text { kenjougo }\end{array}$ & b. Krama alus \\
\hline
\end{tabular}

1. Ragam futsuu/ ragam biasa

Di Jepang terdapat dua jen is ragam tutur yang disebut ragam futsuu dan ragam teinei. Kata futsuu berarti 'biasa' kalimatnya banyak berakhir dengan kata "da" atau "dearu". Ragam futsuu digunakan dalam penuturan diantara anggota keluarga, kawan- 
kawan yang akrab, orang yang berstatus tinggi terhadap yang berstatus lebih rendah, dalam bahasa media massa, makalah dan sebagainya.

M enurut K odansha K okugo Jiten (1966), futsuu adalah 'hiroku ippan ni tsuujiru kotoo kawatte inai koto atari mae'. Pernyataan tersebut men gandung makna bahwa sesuatu yang berhubun gan dengan hal umum yang luas; sesuatu hal yang sangat biasa dan tidak ada yang berubah atau berbeda.

Contoh kalimat ragam futsuu:

a. Kore wa kaban da.

'iki tas'

b. Boku wa taberu. 'aku mangan'

Sedangkan kata teinei berarti sopan, kalimatnya berakhir dengan kata "desu" atau "masu". Ragam teinei dipakai untuk men ghormati secara langsung kepada mitra wicara. Ragam teinei dipakai dalam penuturan antara mahasiswa dan guru, pelayan toko dan tamu, pegawai berpangkat lebih rendah terhadap yag lebih tinggi di kantor, terhadap seseorang yang belum kenal sebelumnya, dalam surat, ditempat formal ataupun dalam rapat.

Contoh kalimat ragam futsuu dan teinei:

\section{Ragam Futsuu}

Kore wa kaban da.

'iki tas'

Boku wa taberu

'aku mangan'

\section{Ragam teinei}

Kore wa kaban desu. 'punika tas'

Watashi wa tabemasu

'kula nedha'

Berikut ini tabel perubahan bentuk futssuu (biasa) ke bentuk teinei (sopan) dalam bahasa Jepang. 


\begin{tabular}{lllll}
\hline NO & $\begin{array}{l}\text { FUTSUU } \\
\text { (NGOKO) }\end{array}$ & Teinei (krama) & Keterangan & Arti \\
\hline 1. & Kaban da & Kaban desu & + desu & Tas \\
2. & Gakusei da & Gakusei desu & + desu & Siswa \\
3. & Iku & Ikimasu & + masu & Pergi \\
4. & Nomu & Nomimasu & + masu & M inum \\
5. & Taberu & Tabemasu & + masu & Makan \\
6. & Okiru & Okimasu & + masu & Bangun \\
7. & Kuru & Kimasu & + masu & Datang \\
8. & Benkyou suru & Benkyoushimasu & + masu & Belajar \\
\hline
\end{tabular}

Dari tabel di atas dapat disimpulkan bahwa ada perubahan yang statis dari ragam futsuu (ngoko) ke dalam bentuk teinei (krama) dalam bahasa Jepang. Sehingga jika dibuat rumus atau formula akan menjadi seperti berikut.

Jenis Kata futsuu (ngoko) teinei (Krama) Arti

1. Kata Benda

Gakusei $\quad+$ da

+ desu

siswa

2. KK kelompok I

Iku

iku >iki

+ masu

pergi

3. KK kelompok II

Taberu taberu tabe + masu makan

4. KK kelompok III
Kuru kuru
ki + masu
datang

Kata kerja dalam bahasa Jepang dibagi menjadi tiga kelompok, yakni kata kerja kelompok I, yaitu kata kerja yang berakhiran, -u, tsu, ru, -mu, -bu, -gu, -nu, -su, -ku, contohnya pada kata iku (pergi) dan nomu (minum). Selanjutnya, kata kerja kelompok II, yaitu kata kerja yang berakhiran eru dan iru, contohnya pada kata taberu (makan) dan okiru (ban gun), yang terakhir adalah kata kerja kelompok III, yaitu kata kerja khusus karena hanya ada dua kata saja, yaitu kata kuru (datang) dan suru (melakukan). Perubahan 
dari ragam futsuu (ngoko) ke ragam teinei (krama) pada jenis kata kerja di atas sudah tetap sesuai dengan formula yang ada.

Jika ditelusuri dari kata asalnya, kata 'ngoko' berasal dari kata "koko". Karena mendapat imbuhan ng-, maka kata koko berubah menjadi ngoko, yang artinya tidak beda dengan kata "kowe" yaitu "kamu", tetapi kasar. Jadi, dapat diartikan bahwa ngoko adalah suatu tataran kata atau kalimat yang tidak mengandung unsur penghormatan. Dalam bahasa Jawa tataran kata biasa disebut tataran tembung.

D ari penjelasan di atas, dapat dilihat bahwajika dalam bahasa Jepang semua kata dari ragam futsuu (ngoko) akan mengalami perubahan dalam ragam teinei (krama) meskipun bukan perubahan kata secara total yang membentuk kata baru, tapi hanya menambahkan verba bantu berupa desu atau masu di akhir kalimat. Verba atau desu akan menempel pada kata benda dan adjektiva, sedangkan verba bantu - masu akan menempel pada kata kerja. Dalam bahasa Jawa, perubahan dari ngoko ke krama lebih variatif. Ada yang tidak men galami perubahan kata sama sekali, tetapi ada pula kata dari ngoko yang berubah total dalam ragam krama sehingga terbentuk kata baru. Dalam bahasa Jepang hampir semua kata futsuu (ngoko) bisa diubah kedalam teinei (krama) maupun karma inggil, tetapi dal am bahasa Jawa kata ngoko ada yang memiliki padanan dalam krama saja tetapi dalam krama inggil padanannya tidak ada meskipun tidak sedikit juga yang memiliki padanan dalam krama dan juga krama inggil. $\mathrm{H}$ al inilah yang kemudian memunculkan perbedaan yang cukup signifikan antara bahasa Jepang dan bahasa Jawa dalam hal perubahan kata dari bentuk ngoko ke bentuk krama.

K eigo dapat diartikan bahasa hormat atau berbicara untuk men ghormati. M en gutarakan rasa hormat kepada mitra wicara dalam berbahasa dapat memakai kata-kata yang sesuai dengan situasi mitra wicara, contoh:

1) Ohirugohan wa, mou meshiagarimashitaka.

Makan siang (nom) part sudah makan

'(A nda) sudah makan siang?' 
2) Taeko san wa irasshaimasuka.

Taeko pronomina part ada

'apakah tuan Taeko ada?'

(Japanese for today:90)

Contoh kalimat di atas mengungkapkan suatu nilai rasa penghormatan. Pembicara menggunakan keigo, yang dalam hal ini pembicara menganggap bahwa mitra wicaranya adalah seseorang yang memiliki derajat sosial yang lebih tinggi dari dia ataupun seseorang yang patut untuk dihormati. Dengan demikian, orang yang diajak berbicara pun akan merasa dihormati dan men ganggap pembicara memiliki budaya bahasa yang bagus.

Sebagai perbandingan dapat dilihat contoh kalimat dibawah ini:

3) Mou, tabeta

Sudah makan

'sudah makan?'

4) Taeko kun wa iru ka

Taeko pronomina part ada katatanya

'(apakah)Taeko ada?'

Orang yang dibicarakan

\section{Pembicara}

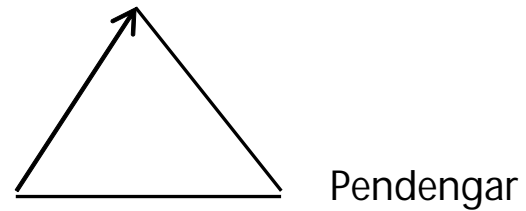

Pada contoh 3) dan 4) pembicara tidak menggunakan ragam keigo, akan tetapi tetap menunjukkan hal atau situasi yang mirip dengan contoh kalimat 1) dan 2) di atas. Pada contoh kalimat ini pembicara menganggap mitra wicaranya seseorang yang sederajat dengan dia atau lebih rendah. $\mathrm{Hal}$ ini menunjukkan bahwa keigo merupakan cara untuk menghormati dan menganggap tinggi posisi mitra wicara, pendengar, serta orang ketiga melalui tuturan. $\mathrm{H}$ al ini dapat digambarkan pada bagan 
di atas. Perhatikan beberapa contoh perubahan kata dari bentuk futsuu (ngoko) ke bentuk teinei (krama) dalam bahasa Jepang berikut ini.

\section{Ragam futsuu (ngoko)}

1. Boku wa supageti o taberu.

'A ku mangan spageti.'

2. Banana wa yasui.

'G edhange murah.'

3. Kinou banana o tabeta.

\section{Ragam teinei (krama)}

Watashi wa supageti o tabemasu.

'Kula nedha spageti'

Banana wa yasui desu.

'Pisangipun mirah'

Kinou banana o tabemashita.

'D hek wingi aku mangan gedhang' 'Kala wingi kula nedha pisang'

Berikut ini adalah tabel kosa kata penanda ragam teineigo (krama) dalam tataran kalimat bahasa Jepang.

\begin{tabular}{lll}
\hline NO & KOSA KATA & KETERANGAN \\
\hline 1. & $\sim$ desu & Terutama jika bersambung dengan nomina dan adjektiva. \\
2. & $\sim$ de gozaimasu & Lebih sopan dari "desu” dan "arimasu” \\
3. & $\sim$ masu & Terutama jika bersambung dengan verba. \\
4. & $\sim$ de arimasu & Dipakai dalam makalah atau pidato. \\
\hline
\end{tabular}

Dari uraian di atas dapat diambil kesimpulan bahwa dalam tataran kata, perubahan bentuk futsuu (ngoko) dalam bahasa Jepang, semua kosa kata seperti kata ben da, kata sifat, maupun kata kerja dapat diubah ke dalam bentuk teinei (krama) dengan menambahkan prefiks "o" atau "go". Dalam teineigo, untuk memperindah ungkapan kata benda yang erat hubungannya dengan kehidupan sehari-hari, prefiks "o" dan "go" banyak sekali dipakai, misalnya pada kata osake, oshi goto, oyasumi, otearai, gohan, dan lain-lain.

$\mathrm{H}$ al ini berbeda den gan bahasa Jawa, karena tidak semua kata dalam ragam ngoko memiliki padanan kata dalam ragam krama, tetapi mun gkin saja padanan kata itu ada dalam krama inggil atau dua-duanya ada. M eskipun demikian ada beberapa cara untuk men gubah kosa kata ragam ngoko ke ragam krama dalam bahasa 
Jawa, yaitu dengan mengganti suku kata terakhir dengan sufiks tertentu seperti contoh berikut ini. Ada beberapa cara pembentukan krama dari tembung ngoko.

1. Mengganti akhir kata dengan -os

Contoh:

Ganti (ngoko) gantos (krama) ganti (arti)

2. Mengganti akhir kata dengan - nten

Contoh:

Pira (ngoko) pinten (krama) berapa (arti)

3. Mengganti akhir kata dengan - bet

Contoh:

Mlebu (ngoko) mlebet (krama) masuk (arti)

4. Mengganti akhir kata dengan -ntun

Contoh:

Pari (ngoko) pantun (krama) padi (arti)

Dalam bahasa Jepang juga terdapat cara lain untuk mengubah kata kerja futsuu (ngoko) ke bentuk sonkeigo (krama inggil) yaitu dengan men gubah suku kata terakhir menjadi bentuk bunyi vocal -a, kemudian menambahkan verba bantu - reru di belakang kata kerja kelompok I, kelompok II, maupun kelompok III.

$\begin{array}{lll}\text { futsuu (ngoko) } & \text { sonkeigo (krama inggil) } & \text { arti } \\ \text { iku (I) } & \text { ika treru } & \text { pergi } \\ \text { taberu (II) } & \text { tabe trareru } & \text { makan } \\ \text { kuru (III) } & \text { ko trareru } & \text { datang }\end{array}$

Contoh:

1) O otosan wa nan ji kaerareru?

'Bapak kondur jam pinten?'

2) Nani o nomaremasen ka?

'N gunjuk punapa?'

Berikut beberapa verba yang termasuk kedalam ragam kenjougo (krama andhap). 
1) Sashiageru [yaru $=$ wen eh $/$ caos]

Kore 0 otoosan sashiageta.

'Iki kaos Bapak'

2) Mooshiageru [iu $=$ kandha]

Atsuku orei mooshiageru

'matur sembah suwun'

3) U kagau [tazuneru =tilik, kiku =krungu, tazuneru =takon]

Raishuu ukagaimasu

'kula bade sowan minggu ngajeng'

A pabila orang lain yang akan kita hormati menjadi tujuan atau objek dari perbuatan kita, atau perbuatan dari anggota keluarga kita, bisajuga untuk orang yan g posisi atau usianya lebih rendah, maka kata bendanya diberi prefis "o" atau "go". Seperti halnya dalam sonkeigo, kata kerja dalam ragam sonkeigo juga dapat diberi prefiks " 0 ". hal ini bertujuan untuk merendahkan diri terhadap orang lain. K enjougo (krama andhap) itu sendiri merupakan imbangan dari ragam sonkeigo (krama inggil). Jadi, ketika mitra wicara berbicara men ggun akan ragam bahasa sonkeigo (krama inggil) maka pembicara akan menggunakan ragam bahasa kenjougo (krama andhap) untuk menghormati mitra wicaranya.

\section{SIMPULAN DAN SARAN}

Dewasa ini anak-anak muda di Jepang menghindarkan diri dari pemakaian kenjougo (krama andhap). Ini mungkin terjadi karena anak-anak muda masa kini suka menonjolkan diri dan merasa tidak pantas merendahkan diri kepada orang lain. $\mathrm{Hal}$ ini tercermin dari film-film Jepang sekarang ini. Sedangkan menurut survei penulis, hampir sebagian besar siswa Indonesia yang mempelajari bahasa Jepang karena diawali den gan menyukai film-film Jepang. $\mathrm{Hal}$ ini tentu saja sangat memengaruhi siswa yang mempelajari bahasa Jepang, sehingga sering timbul kesalahan-kesalahan yang dilakukan dalam pemilihan varian dalam hal undak usuk khususnya, baik itu dalam bahasa lisan atau tulis. Begitu juga dalam bahasa Jawa akhir-akhir ini, bahasa 
Indonesia telah dengan mantap digunakan dan terusberkembang dengan baik dalam ranah keluarga maupun di luar keluarga, dan sebagai akibatnya bahasa Jawa semakin tersingkir terutama dari ranah keluarga masyarakat Jawa sen diri, meskipun belum sampai ke tahap yang lebih besar, sehingga unggah ungguh basa bisa terancam kel estariannya.

Dari hasil uraian di atas, terhadap penggunaan tingkat tutur bahasa Jepang dan bahasa Jawa dapat dilihat bahwa Jawa mempunyai tingkat tutur ngoko, krama, dan madya dan masingmasing terbagi lagi ke dalam beberapa sub tingkat dan tiap-tiap tingkah diberi mana mudha karma, basa antya dan sebagainya. Adapun dalam bahasa Jepang terdapat dua tingkat tutur, yaitu ragam futsuu dan ragam teinei. Kedua ragam tersebut mempunyai kadar hormat yang berbeda-beda, tetapi tidak diberi nama. Pemilihan varian undak usuk dalam bahasa Jepang secara garis besar dapat disimpulkan sebagai berikut.

a. H adir atau tidaknya orang yang hendak dibicarakan

b. Hubungan atas-bawah, meliputi hubungan atas-bawah dalam organisasi, hubungan atas-bawah delam status sosial, umur, junior-senior

c. Hubungan pemberi jasa-penerima jasa

d. H ubungan antara yang berkuasa atau memiliki kekuatan

e. Hubungan akrab-jauh

f. Terhadap wanita

g. Formal atau tidak formal

h. Hubungan "dalam" dan "luar" (dalam keluarga pembicara atau orang yang berada diluar keluarga pembicara).

D alam bahasa Jawa pemilihan varian undak usuk dipen garuhi

oleh beberapa faktor diantaranya:
a. Faktor umur
b. Faktor Kekerabatan (peprenahan)
c. Faktor sosial (drajat pangkat)
d. Faktor kekayaan (drajat semat)
e. Faktor keturunan (darah utawi trah)
f. Faktor kualitas pribadi (luhuring pribadi) 


\section{g. Faktor pertemuan (tetepangan)}

Penelitian ini adalah penelitian kontrastif tentang bahasa Jepang dan bahasa Jawa dipandang dari segi undak usuk atau tingkat tuturnya yangjangkauannya masi $\mathrm{h}$ luas atau dengan kata lain masih eksploratif. Oleh karena itu penelitian kontrastif ini masih perlu ditindak lanjuti dengan penelitian lain yang serupa namun memiliki ruang lingkup yang lebih sempit agar analisis yang dilakukan dapat mencapai hal yang lebih mendasar atau bersifat developmental.

\section{E. DAFTAR PUSTAKA}

Bunkachou. 1971. Taiguu Hyogen. Tokyo: Oukurashou Insatsu Kyoku.

Gorys, Keraf.1980. Tata Bahasa Indonesia. Flores: Nusa Indah.

Harjawiyana, Haryana dan Supriya Th. 2001. Marsudi Unggah Ungguh Basa Jawa. Yogyakarta: Kanisius

Jack, Richard. 1985. Longhman Dictionary of Applied Linguistic. Bungay: Longman Group. James, Carl. 1986. Contrastive Analysis. Harlow Ersex: Longman Group Ltd.

Kridalaksana, Harimurti. 2001. W iwara Pengantar Bahasa dan Kebudayaan Jawa. Jakarta: PT Gramedia Pustaka Utama

Purwadi, dkk. 2005. Tata Bahasa Jawa. Yogyakarta: Media Abadi

Soetomo, Istiadi.1994. Kuliah Sosiolinguistik Hand Out. Semarang: Fakultas Sastra Undip.

Sudaryanto.1981. Metode dan Teknik Pengumpulan Data. Yogyakarta: Gajah Mada University press. 